\title{
Peculiarities of mining and technical conditions for construction and operation of Kuznetskovskiy tunnel on the far eastern railway
}

\author{
Sergey Kvashuk ${ }^{1, *}$, Boris Smyshlyaev ${ }^{1}$, and Vasiliy Trunev $^{2}$ \\ ${ }^{1}$ Far East State Transport University, 47 Seryshev Str., Khabarovsk, 680021, Russia \\ ${ }^{2}$ Research Center "Bamtonnel" (NIC "Bamtonnel", Ltd), 1, building 3 of Komsomolsky Avenue, \\ Novosibirsk, 630004, Russia
}

\begin{abstract}
Kuznetsovskiy tunnel is built in the pass section of SikhoteAlin Ridge on the Pivan-Sovetskaya Gavan leg of the Far Eastern Railway route, Russia. The tunnel axis is crossed by a system of faults of various capacities. The fault zones are associated with increased fracturing, reduced stability, abundant water inflows in some places, the threat of dumping, intense silicification and sulfide mineralization. The monitoring data obtained by natural pulsed electromagnetic field of the Earth (NPEFE) and dipole electromagnetic proliferation (DEMP) methods made it possible to come to a conclusion about the real picture of the development and to make forecast of the rock pressure, as well as the dynamics of groundwater entering to the workings for the further tunnel's safe construction and operation.
\end{abstract}

\section{Introduction}

The construction of the Pivan - Sovetskaya Gavan railway line was carried out in the forties of the 20th century in accordance with "lightened" technical standards. The Sikhote-Alin ridge pass is the most complicated part of the route where slopes of the longitudinal profile with gradients up to $28-29 \%$ were arranged. At the top of the pass it was built a $413.30 \mathrm{~m}$ length tunnel, that is in an unsatisfactory technical condition nowadays. Later, in 2000, due to the increase of cargo flows and also due to the increase in the mass of trains up to 5-6 thousand tons, it was decided to reconstruct the overpass with construction of new Kuznetsovskiy tunnel. The tunnel was designed as duo-pitched. The total length of the structure is $3890 \mathrm{~m}$, its maximum depth is $355 \mathrm{~m}$. The tunneling was carried out by tunnel boring machine LOVAT RME 375 SE.

Tunnel lining has a circular outline with an external diameter of $9195 \mathrm{~mm}$ and consists of 7 reinforced concrete blocks. The length of the ring is $1500 \mathrm{~mm}$. The design of the ring is shown in Figure 1. To ensure a safe environment of the tunnel construction, as well as its subsequent normal operation for a long time it was necessary to carry out a thorough study

\footnotetext{
*Corresponding author: s_kvashuk@mail.ru
} 
of geo-engineering and hydrogeological conditions of the rock mass. In addition, during the tunneling, it was proposed to monitor the gallery stability, to make forecasts of the rock pressure development and the inflow of groundwater into the tunnel.

The above jobs were performed by specialists of the Far East State Transport University, (DVGUPS, Khabarovsk, Russian Federation) and "Research Center Bamtonnel", Ltd ("NIC Bamtonnel", Ltd, Novosibirsk, Russian Federation) during the whole construction period of Kuznetsovskiy tunnel.
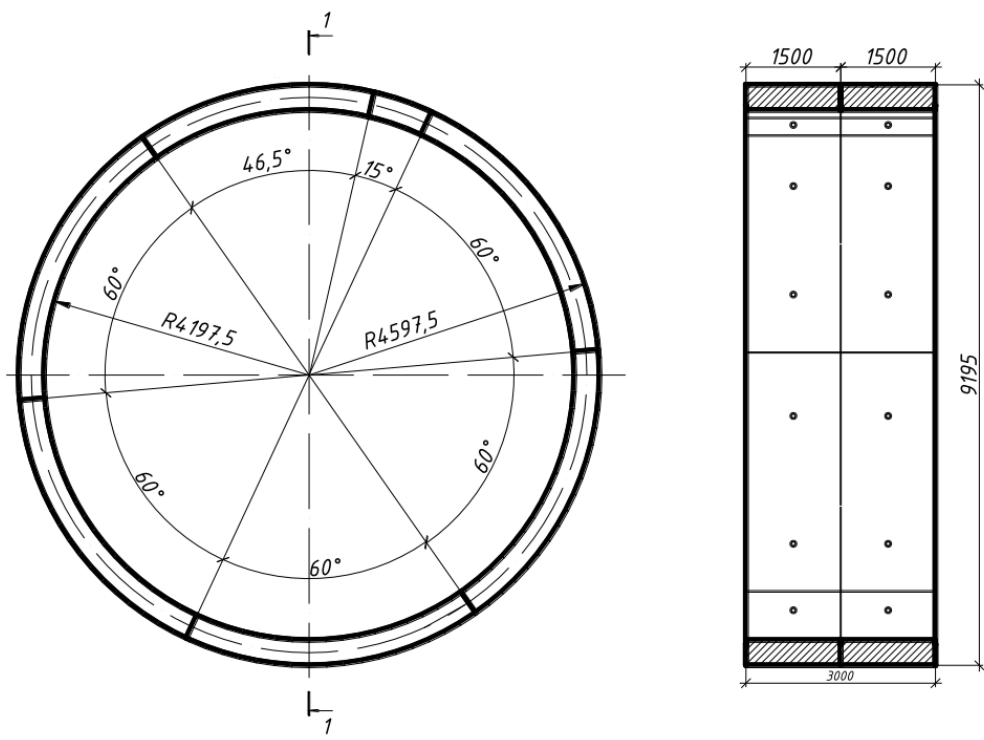

Fig. 1. Kuznetsovskiy Tunnel lining rings design.

\section{Results of the study}

Sikhote-Alin fold system is part of the south engineering-geological region of the Far East, and has its closure on the east coast of the East-Sikhote-Alin volcanic area [1].

The geological structure of the mass was represented by the contact of terrigenous rocks with effusives of Early Cretaceous age. Terrigenous rocks are represented by the Pivan, Pioneer (rhythmic interbedding of heterogeneous grained sandstones and siltstones) and Udomin Formations (gravelites, conglomerates and sandstones) separated by disruptive disturbances. The terrigenous base is characterized by an alternation of bundles of rhythmically interbedded layered siltstones and parallel bedded (rarely cross-bedded) sandstones with a component thickness from $0.5-3 \mathrm{~cm}$ to $20-40 \mathrm{~cm}$. Occasionally, strata of black massive siltstones up to $30 \mathrm{~m}$ thick and fine grained sandstones with a thickness of up to $40 \mathrm{~m}$ are fixed. Layering of rocks has a predominantly steep drop $\left(60-90^{\circ}\right)$. Stretching of lamination from sublatitudinal to NE $\left(240-300^{\circ}\right)$.

With the direction of the tunnel stretching $320^{\circ}$, the main strike of the stratification deviates to the left of the tunnel route by $20-60^{\circ}$. Such conditions are favorable for tunneling. The averaged basic parameters of the physical and mechanical properties of rocks are presented in the Table 1.

The rocks of the mountain mass are classified as strong and very strong, very dense according to GOST 25100-2012. Siltstones have the greatest compressive strength, and sandstones -- the greatest tensile strength. The weak strength of sandstones is due to the 
high degree of fracturing. In homogeneous samples of sandstones, the compressive strength limit was $280 \mathrm{MPa}$, and the tensile strength was up to $22 \mathrm{MPa}$. Density of rocks differs slightly $\left(2.63-2.72 \mathrm{~kg} / \mathrm{dm}^{3}\right)$. According to the toughness, the rocks of the tunnel belong to the 1-3 categories according to the M.M. Protodyakonov scale from the highest degree of toughness to strong. The reliability of the rocks properties determining for a given number of samples is $80-90 \%$.

Table 1. Physical and mechanical properties of rocks that hold the Kuznetsovskiy tunnel.

\begin{tabular}{|c|c|c|c|c|c|c|c|}
\hline \multirow{2}{*}{$\begin{array}{c}\text { Physical and } \\
\text { mechanical } \\
\text { properties / } \\
\text { Rock samples }\end{array}$} & $\begin{array}{c}\text { Density, } \\
\mathrm{t} / \mathrm{m}^{3}\end{array}$ & $\begin{array}{c}\text { Compression } \\
\text { in dry } \\
\text { condition }\end{array}$ & $\begin{array}{c}\text { Compression } \\
\text { in water - } \\
\text { saturated state }\end{array}$ & $\begin{array}{c}\text { Elastic } \\
\text { tensil } \\
\mathrm{e}\end{array}$ & $\begin{array}{c}\text { Deformation } \\
\text { modulu, } \\
\text { MPa } * 10^{4}\end{array}$ & $\begin{array}{c}\text { Modulus, } \\
\text { MPa * } 10^{4}\end{array}$ & $\begin{array}{c}\text { Toughness } \\
\text { coefficient }\end{array}$ \\
\hline Sandstones & 2.662 & 185.78 & 121.53 & 12.37 & 1,242 & 1.44 & 8,578 \\
\hline $\begin{array}{c}\text { Sandstones with } \\
\text { interbeds of } \\
\text { siltstone }\end{array}$ & 2.649 & 77.13 & 75.01 & 5.83 & 1,044 & 1.19 & 7.71 \\
\hline $\begin{array}{c}\text { Intercalation } \\
\text { of siltstones and } \\
\text { sandstones }\end{array}$ & 2,633 & 105.82 & 152.39 & 6.87 & 1,213 & 1.336 & 10.58 \\
\hline Siltstones & 2.652 & 112.87 & 52,797 & 9.47 & 1.237 & 1.536 & 11.29 \\
\hline $\begin{array}{c}\text { Sedimentary } \\
\text { breccias }\end{array}$ & 2.642 & 104.029 & 70.85 & 8.87 & 1.038 & 1.408 & 10.4 \\
\hline Andesite tuff & 2,715 & 89.13 & 75.5 & 8.47 & 1.403 & 1,417 & 8.91 \\
\hline Rhyolite tuff & 2,676 & 80.23 & 47.08 & 4.65 & 1.153 & 1.157 & 8.02 \\
\hline
\end{tabular}

The mountain mass enclosing the tunnel is broken by a system of faults of different thicknesses in the northwest and northeast (in the south-eastern part of the area) strike. The total thickness of the faults is $334 \mathrm{~m}$, that is $8.5 \%$ of the length of the tunnel. The largest zone (leg 2246-2286 m) has a thickness of about $40 \mathrm{~m}$. A regular change in the physical and mechanical properties and stability of rocks with changes from monolithic rock to tectonically fractured is recorded. Thus, the compressive strength of sandstone, not weakened by cracks, is $160 \mathrm{MPa}$, and for the fractured sandstone is $45 \mathrm{MPa}$. Proceeding from the fact that in some areas the rock is weakened by cracks to the fragmented state, the differences in physical and mechanical properties can reach dozens of times. Accordingly, the stability of the rock changes from stable and medium stability to weak stability and unstable [2]. All zones are associated with increased fracturing, reduced rock stability, dumps and intense silicification and sulfide mineralization. The water inflows in the zones as a whole are small, in some places are plentiful, reaching $55 \mathrm{~m}^{3} / \mathrm{h}$ (leg 2485-2489 m). After the lining installation, water leaks from intertubing seams and technological holes were recorded [3]. The strength properties of fractured rocks differ significantly from monolithic analogues. This creates heterogeneity of the environment, complicating the characteristics of the array as a whole and designing the tunnel structures. Despite significant differences in strength properties, the rocks are characterized as strong. Extensive sections of a sharp decrease in strength were not observed. Basically, these are relatively small (up to $40 \mathrm{~m}$ ) tectonic fracture zones [4]. Monitoring of the stress-strain state of the mountain mass that holds the tunnel and also the forecast of groundwater inflow was carried out during the entire construction period, from 2010 to 2012 quarterly. The monitoring was carried out by natural pulsed electromagnetic field of the Earth (NPEFE) and dipole electromagnetic proliferation (DEMP) methods [5]. Electromagnetic radiation intensity is a measure of the tunnel lining and host rock tension level, and the results of dipole electromagnetic profiling shows the change in time of the mountain mass, containing underground excavations, watering 


\section{Interpretation of results and conclusions}

The results of the monitoring work are presented in Figures 2 and 3.

With sufficient reliability for practical purposes the analysis of the materials obtained from the studies makes it possible to state the following:

- the average level of radiation intensity of the NPEFE remains practically constant, and the places of local intensity increases are related to the construction work (Fig. 2). In general, the geodynamic state of the mountain mass in the tunnel zone during the entire construction period can be characterized as stable;

- the profiling data collected by the DEMP method (Figure 3) allows to analyze the dynamics of groundwater inflow of to the tunnel both as in its sections so as in the corresponding periods of the year.

- the completed studies of the geological structure of the mountain mass, enclosing the tunnel, adequately locate the zones of tectonic dislocations, weakened layered and highly fractured rocks along the route of the new Kuznetsovskiy tunnel.

- the monitoring of the mountain mass state along the tunnel route, performed by the NPEFE and DEMP methods during the construction period, provided actual data on the development and gave possibility to make forecast of rock pressure, as well as the dynamics of groundwater supply to the mine.

- the received data provided, normal and safe work of the tunnel boring machine along the tunnel route, and allowed to avoid unforeseen situations during its construction.

- received information on the engineering-geological conditions of Sikhote-Alin ridge pass and works on rocks monitoring are relevant during the operation of the constructed tunnel, as well as in other underground transportation facilities of the district, including the planned construction of the second stage tunnel transition during the construction of the second tracks on the railway route Komsomolsk-na-Amure - Sovetskaya Gavan.

Western Portal

Eastern portal

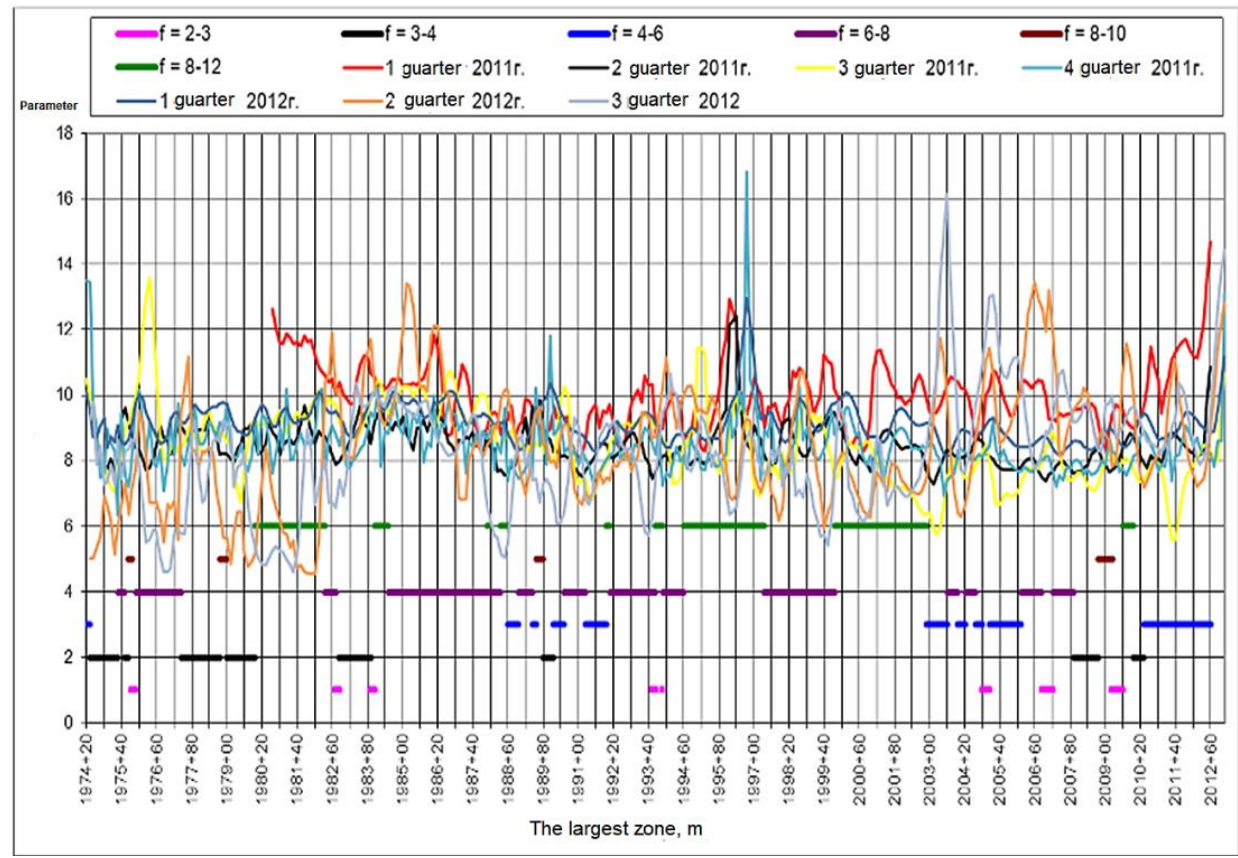

Fig. 2. Rock formations of different toughness apparent electrical resistance changes on sections of Kuznetsovskiy tunnel, f- toughness coefficient by M.M. Protodyakonov. 


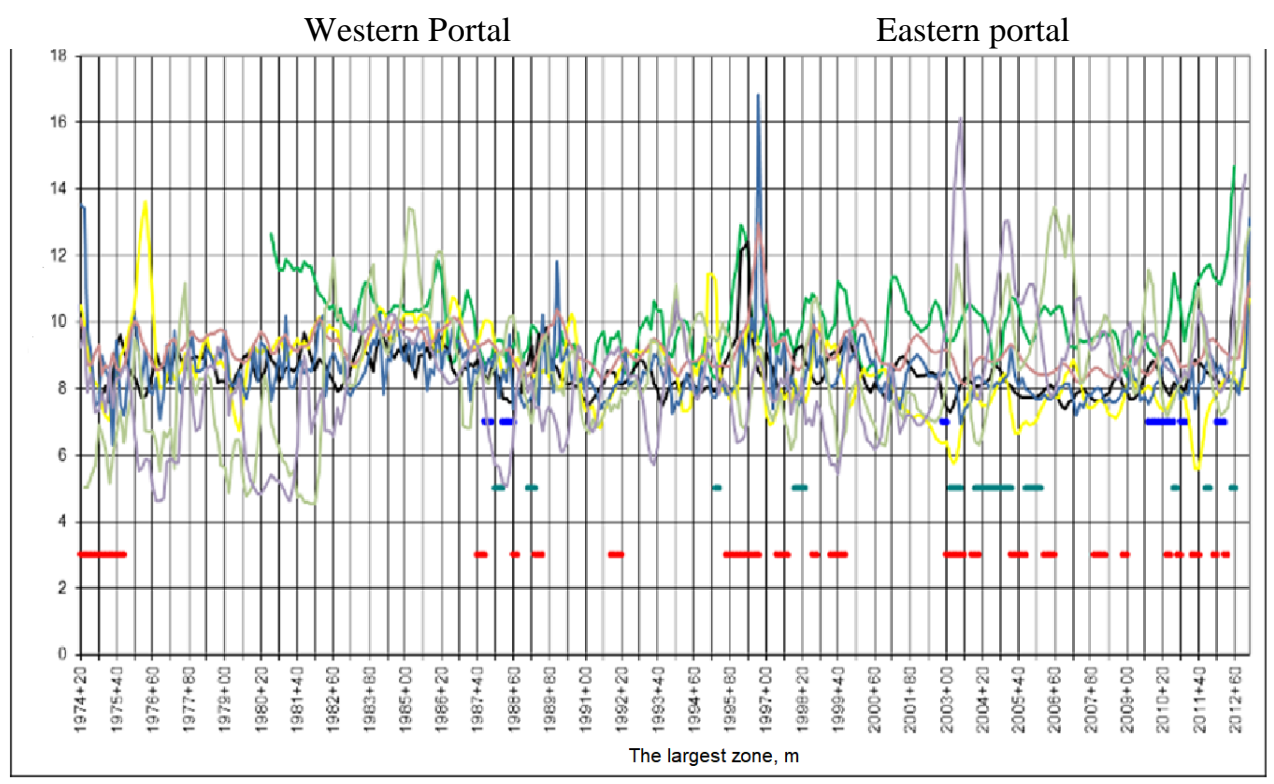

Fig. 3. Rock formations electrical resistance change and water cut by sections of Kuznetsovskiy tunnel.

\section{References}

1. E.G. Chapovskiy, Engineering geology of the USSR, Far East 4, 501 (1977)

2. S.V. Kvashuk, V.V. Kulakov, Engineering-geological and hydro-geological conditions of the projected Kuznetsovskiy tunnel junction (northern Sikhote-Alin), XII scientific readings named after Professor N.I. Tolstikhin (Saint-Petersburg, 2006)

3. G.A. Zlobin, V.V. Kulakov, Zh- 1 Geoecology. Engineering geology. Hydrogeology. Geocryology 4, 304-316 (2014)

4. S.V. Kvashuk, G.A. Zlobin, IV All-Russian Scientific Conference with the participation of foreign scientists, IGD FEB RAS 1, 45-51 (2011)

5. K.P. Bezrodniy, Yu.S. Isaev, A.D. Basov, Metro and tunnels 3, 28 - 30 (2013) 